\title{
Os jingles como formas simbólicas estratégicas de persuasão político-eleitoral
}

\author{
Fábio Hoffmann ${ }^{\mathrm{I}}$ \\ Everton Rodrigo Santos ${ }^{\mathrm{II}}$
}

\begin{abstract}
Resumo: O objetivo deste trabalho é fazer uma análise dos jingles políticos como formas simbólicas estratégicas de persuasão político-eleitoral. Para isto, se procura analisá-los inseridos em um contexto histórico específico e social estruturado. É do contexto sócio-histórico que o briefing se vale para formular a letra/mensagem do candidato ou governo composto com a música/melodia. Mais do que uma peça publicitária para elevar qualidades ou combater conceitos, portanto, o jingle é recepcionado por determinantes de um campo em permanente disputa por capital político. Campo de poder que concatena diferentes formas de produzir e recepcionar os símbolos presentes nesse embate. Este trabalho argumenta que compreender o conjunto dos mecanismos simbólicos dentro dos quais são criados, recepcionados e transmitidos os jingles políticos constitui um elemento primordial para determinar suas chances de ser bem sucedido ou não.
\end{abstract}

Palavras-chave: Jingles políticos, formas simbólicas, marketing político.

\section{The jingles as strategic symbolic forms of political-electoral persuasion}

Abstract: The objective of this work is to make an analysis of political jingles as strategic symbolic forms of political-electoral persuasion. For this, we try to analyze them inserted in a specific historical context and structured social. It is from the sociohistorical context that the briefing is used to formulate the letter / message of the candidate or government composed with the music / melody. More than a publicity piece to elevate qualities or combat concepts, therefore, the jingle is received by determinants of a field in permanent dispute by political capital. Field of power that concatenates different ways of producing and receiving the symbols present in this clash. This paper argues that understanding the set of symbolic mechanisms within which political jingles are created, received, and transmitted constitutes a prime element in determining their chances of success or failure.

Keywords: Political jingles, symbolic forms, political marketing.

Artigo recebido em 07/08/2017 e aprovado em 15/10/2017.

Cadernos do Tempo Presente, São Cristóvão-SE, v. 08, n. 04, p. 27-38, jul./dez. 2017| http://www.seer.ufs.br/index.php/tempo 


\section{OS JINGLES COMO FORMAS SIMBÓLICAS ESTRATÉGICAS DE PERSUASÃO POLÍTICO- ELEITORAL}

\section{FÁBIO HOFFMANN E EVERTON RODRIGO SANTOS}

\section{Introdução}

Não se pode negar a tendência para a convergência midiática ${ }^{\text {III }}$ e o apelo para a concentração da comunicação política contemporânea na imagem e no vídeo em detrimento do texto. Estas formas de propagação de mensagem na indução do comportamento dos indivíduos e, principalmente neste trabalho, dos eleitores, predominam a pauta de uma campanha eleitoral ou o marketing de um governo, ou ainda, uma agenda de ação parlamentar.

Este trabalho, no entanto, concentra-se mais especificamente em outra ferramenta de comunicação política: o jingle político. Essa ferramenta tem ajudado a construir, orientar e captar uma ampla gama de significações presentes no imaginário popular. Os jingles são criados para atingir um público majoritário quando a eleição é para prefeito, governador, senador ou presidente da república, e proporcionalmente majoritário dentro do coeficiente que a zona eleitoral apresenta quando é uma eleição para vereador e deputado estadual e federal.

Este trabalho pretende contribuir para o aprofundamento do conhecimento em relação a esse campo, ainda pouco explorado na academia, que é o da comunicação política e eleitoral, representado pela ferramenta dos jingles políticos. Embora exista a possibilidade de estudar esse objeto com um enfoque multidisciplinar, buscamos orientar este trabalho dentro da tradição da ciência política.

Primeiramente é feito uma breve revisão histórica do surgimento e da evolução dos jingles políticos no Brasil, dando destaque para a consolidação do jingle como ferramenta de disputas por espaços no campo do poder político. Após, é apontado as limitações no uso do conceito de briefing para o estudo aprofundado dos jingles, delimitando-o e o qualificando até chegar ao conceito de formas simbólicas de Thompson $^{\text {IV }}$. É a partir do conceito de formas simbólicas que se entende como os jingles são recepcionados pelos eleitores, através de uma valorização composta na homologia funcional de Bourdieu ${ }^{\mathrm{V}}$. Na sequencia ocorre uma exposição sobre a força dos jingles políticos como mensagem persuasiva, usando para esse fim alguns exemplos práticos do Brasil.

\section{Breve histórico no uso dos jingles no campo da política no Brasil}

O surgimento do jingle político no Brasil está intimamente relacionado ao surgimento e abrangência do uso dos meios de comunicação, mais especificamente, o rádio. O início do uso comercial do rádio no Brasil aconteceu em 1922. Primeiramente restrito aos centros urbanos devido à dificuldade gerada pela extensão territorial brasileira, e depois ampliado paulatinamente dada à importância estratégica desse meio de comunicação para o controle e desenvolvimento social e político do país.

Os primeiros jingles políticos acompanharam a evolução do rádio, e em 1929 surgiu o jingle Seu Julinho Vem, composto por Francisco José Freire Júnior e gravado por Francisco Alves para a campanha de Júlio Prestes do Partido Republicano Paulista (PRP) em 1930. No ano seguinte apareceu $G E$ - Ge de Lamartine Babo, gravada em 1931 por Almirante e Bando dos Tangarás para Getúlio Vargas do Partido Republicano Riograndense (PRR). Esses dois jingles são tidos como precursores dos modernos jingles políticos ${ }^{\mathrm{VI}}$.

Duas ações do Governo Provisório de Getúlio Vargas (1930-1932) impactariam o cenário social e político: a primeira veio através do decreto $\mathrm{n}^{\circ} 20.047$, de 27 de maio

Cadernos do Tempo Presente, São Cristóvão-SE, v. 08, n. 04, p. 27-38, jul./dez. 2017| http://www.seer.ufs.br/index.php/tempo 


\section{OS JINGLES COMO FORMAS SIMBÓLICAS ESTRATÉGICAS DE PERSUASÃO POLÍTICO- ELEITORAL}

\section{FÁBIO HOFFMANN E EVERTON RODRIGO SANTOS}

de 1931 tratou de regulamentar o uso do rádio, permitindo seu uso (embora de modo limitado) também para fins comerciais; a segunda foi o código eleitoral de 1932, trazendo importantes mudanças, como a introdução do voto feminino, por exemplo. Em 1936, em vista da possibilidade de haver eleições nacionais, dois candidatos postulados aparecem com força: Armando Sales de Oliveira (o Seu Manduca) e Osvaldo Aranha (Seu Vavá). Silvio Caldas grava na Odeon a marchinha espelhada em jingle A Menina Presidência, na qual antecipa os rumos no comando da nação, que continuaria nas mãos de Vargas.

Em 1945, quando volta a serem realizadas eleições nacionais, após um intervalo de quinze anos, aparecem os jingles de Eurico Dutra do Partido Social Democrático (PSD), Marmiteiro Marmiteiro, e o do Brigadeiro Eduardo Gomes da União Democrática Nacional (UDN), Salve Salve o Brigadeiro. Mas foi na eleição de em 1951 com o jingle Retrato do Velho, gravado por Francisco Alves para a campanha de Getúlio Vargas, já no Partido Trabalhista Brasileiro (PTB), que essa forma de comunicação alcança status de ferramenta estratégica na comunicação de uma campanha eleitoral. É nesse jingle que alguns elementos e atributos da imagem de Vargas buscam projetar na população uma lembrança das suas principais bandeiras, dentre as quais a do trabalho com toda a legislação trabalhista criada pelo seu governo.

Para a campanha de Juscelino Kubitschek do Partido Social Democrático (PSD) em 1955 é criado o jingle Há 400 Anos A Dormir, que leva o mineiro à vitória nessas eleições. No pleito seguinte, contudo, é criado um dos mais famosos e impactantes jingles políticos de todos os tempos: é o Varre Varre Vassourinha de Jânio Quadros do Partido Trabalhista Nacional (PTN), que virou febre, pois canalizava a percepção popular de corrupção generalizada que o governo anterior acentuara a partir dos vultosos gastos na construção de Brasília. Nesta eleição teve ainda o jingle Caixinha do Adhemar feito para o candidato Adhemar de Barros, no intuito de combater às críticas dos adversários sobre o desvio de recursos públicos.

Com o Golpe Militar em 1964 e o controle da competição política pelos militares, os jingles como ferramentas estratégicas eleitorais somente voltam em 1989. No entanto, é bom observar que durante a Ditadura Militar houve marchinhas e jingles políticos usados para promover o governo militar bem como a apropriação de músicas como Pra Frente Brasil, usadas para a exaltação do sentimento de nacionalismo e igualmente do regime.

É em 1989, na primeira eleição direta para a Presidência da República após uma interrupção de quase trinta anos, que os jingles se afirmam como peça publicitária estratégica das campanhas eleitorais modernas. Nessa eleição temos o maior número de candidatos (22), e todos os principais presidenciáveis possuíam jingles bem elaborados. O destaque desta eleição é o jingle de Hilton Acioli, Sem Medo de Ser Feliz, feito para o candidato Luís Inácio Lula da Silva do Partido dos Trabalhadores (PT), que fora projetado para refazer uma imagem pré-existente de um político intransigente e raivoso, principalmente no seu posicionamento em relação à dívida externa. Nestas eleições teve ainda o jingle de Edgard Poças Juntos Chegaremos Lá para a candidatura de Afif Domingos (PL) que igualmente conseguiu grande empatia do público, embora não dos eleitores.

A partir das eleições de 1989, portanto, que é dada uma atenção cada vez maior ao contexto sócio-histórico para a formulação do jingle. Em 1994 é criado o jingle de Nizan Guanaes, Sérgio Campanelli, Sérgio Mineiro e Cézar Brunetti Levanta a Mão para Fernando Henrique Cardoso, candidato do Partido da Social Democracia Brasileira

Cadernos do Tempo Presente, São Cristóvão-SE, v. 08, n. 04, p. 27-38, jul./dez. 2017| http://www.seer.ufs.br/index.php/tempo 


\section{OS JINGLES COMO FORMAS SIMBÓLICAS ESTRATÉGICAS DE PERSUASÃO POLÍTICO- ELEITORAL}

\section{FÁBIO HOFFMANN E EVERTON RODRIGO SANTOS}

(PSDB), interpretado na voz de Dominguinhos. Este jingle tinha como função destacar o preparo de FHC para comandar o país numa trajetória econômica favorável depois de anos de inflação galopante (FHC já vinha fazendo um marketing no caminho de se consolidar através do Plano Real), e a voz de Dominguinhos e sua sanfona também pretendia ampliar a penetração no eleitorado do nordeste.

Concorrendo à reeleição em 1998, FHC foi o primeiro candidato pósredemocratização a poder formular um jingle que tivesse como mensagem central a continuidade, tendo para este fim o jingle Levanta a Mão. No pleito seguinte, Lula é eleito com um conjunto de jingles, entre os quais, uma adaptação de Sem Medo de Ser Feliz. No entanto, é na campanha de sua reeleição que surge um jingle bem original, e com grande força persuasiva: é o Deixa o Homem Trabalhar de Lázaro do Piauí. A exemplo do jingle de reeleição de FHC (1998), o de Lula em 2006 também busca ampliar a penetração no eleitorado do nordeste. Jingle bem elaborado, o Deixa o Homem Trabalhar conjugava diferentes elementos, entre os quais o sucesso econômico e o impacto positivo das políticas sociais para a população carente e a sociedade em geral.

Em 2010 surge um cenário novo com a necessidade de se formular um jingle que buscasse expressar uma continuidade aperfeiçoada que seria levada a cabo por Dilma Rousseff, candidata do PT para suceder Lula. O jingle Para o Brasil Seguir Mudando buscava, portanto, projetar um caráter de continuidade com mudanças pontuais, destacar a sua contribuição na participação do Governo Lula e o apoio deste à sua candidatura, destacando também o fato de ser mulher, a fim de canalizar um sentimento de apoio de gênero ${ }^{\mathrm{VII}}$. José Serra do PSDB, por outro lado, construiu seu jingle Serra é do Bem com elementos que projetavam atributos e qualidades pessoais para o cargo de presidente, fazendo, inclusive, um trocadilho, de que ele "fazia bem à saúde e não havia contraindicação", buscando sensibilizar a memória do eleitor da sua trajetória como ministro da saúde do segundo Governo FHC.

Em 2014, Dilma Rousseff (PT) altera caracteres de continuidade do jingle Dilma Coração Valente que passa a projetar uma mensagem de resposta à estagnação econômica pela qual o Brasil passava. Aécio Neves do PSDB através de um conjunto de jingles, dentre os quais o Bem Vindo, tinha uma mensagem (não muito clara) de união e força. Marina Silva do Partido Socialista Brasileiro (PSB) apresentava o jingle Não Vamos Desistir do Brasil, onde tentou reunir os mais diversos elementos em uma mensagem de esperança, portanto menos pragmática.

\section{O jingle político como forma simbólica}

O jingle político é uma peça publicitária que procura elevar as qualidades de um candidato, combater um conceito, ou ainda, reforçar uma ideologia, o marketing de um governo ou mandato parlamentar ${ }^{\mathrm{VIII}}$. No entanto, esta é uma definição conceitual atribuída pelos que se ocupam do campo da publicidade, do mercado prático. Segundo esta concepção o jingle nasce do briefing e é uma mensagem cantada, constituída como parte integrante do conjunto de peças publicitárias de um marketing de campanha eleitoral ou de governo.

Cadernos do Tempo Presente, São Cristóvão-SE, v. 08, n. 04, p. 27-38, jul./dez. 2017| http://www.seer.ufs.br/index.php/tempo 


\section{OS JINGLES COMO FORMAS SIMBÓLICAS ESTRATÉGICAS DE PERSUASÃO POLÍTICO- ELEITORAL}

\section{FÁBIO HOFFMANN E EVERTON RODRIGO SANTOS}

Figura 1: visão publicitária do processo de formulação do jingle político

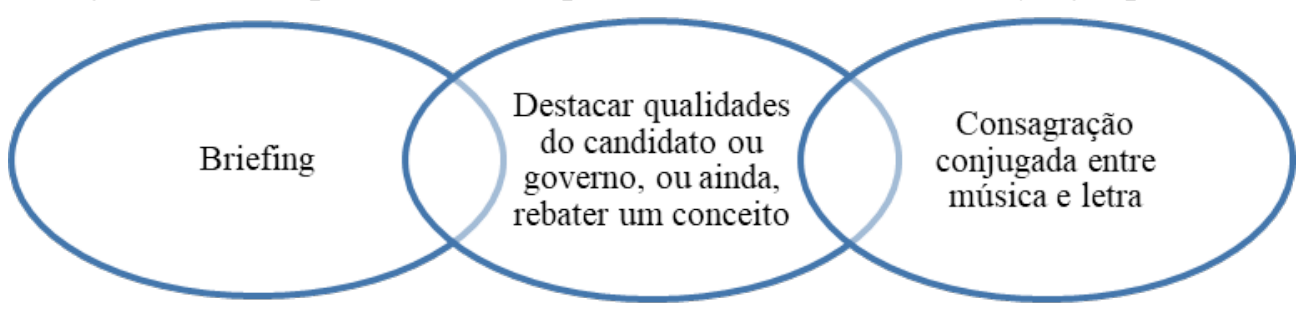

Fonte: elaborado pelo autor.

Como objeto de manifestação de comunicação e poder, no entanto, o jingle assume outras caracterizações, uma vez que ele surge de um mercado que possui demandas das mais diversas, apresentando por esse motivo reflexos de determinados traços sociais estruturais em sua constituição. Alguns traços permitem estabelecer avanços e limites para que o jingle possa ser produzido, comercializado e, principalmente, recepcionado pelo público-alvo.

Este trabalho procura explicar a mobilização dos sentidos da sociedade brasileira a partir da estratégia de produção do jingle político constituído como formas simbólicas. Para essa tarefa recorre-se a alguns estudos e conceitos já consagrados, construídos como instrumentos de análise das produções culturais de massa, da qual o jingle, nessa compreensão é parte integrante.

Dessa forma, quando se fala em "mobilização dos sentidos", trata-se da produção de formas simbólicas, suas produções, transmissões e recepções ${ }^{\mathrm{IX}}$. Formas simbólicas constituem um amplo conjunto de fenômenos significativos como gestos, ações, manifestações verbais ou escritas, imagens, músicas, vídeos e, portando, o objeto de estudo deste trabalho, os jingles. Nesse sentido é apropriado o que Thompson (2011, p. 181) aborda como concepção estrutural da cultura, ou seja, compreender as formas simbólicas a partir de um ângulo que dê atenção tanto ao seu caráter simbólico, como ao fato de tais formas estarem sempre inseridas em um contexto histórico-específico e social estruturado. Essa concepção permite então avançar no entendimento da criação do jingle político inserido em uma lógica de produção cultural de massas, criado, transmitido e recepcionado a partir de um contexto histórico específico, que cada conjuntura apresenta, e social estruturado, dado pelos traços que a sociedade carrega.

Figura 2: o jingle político como formas simbólicas

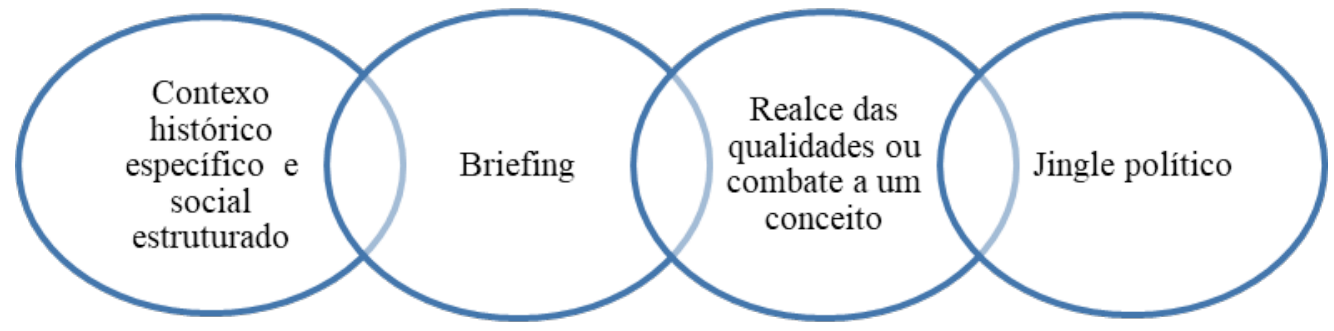

Fonte: elaborado pelo autor.

A produção de jingles políticos, portanto, necessita encontrar nexo relativo às aspirações e demandas existentes na sociedade. Todavia, mais do que isso, precisa também estabelecer uma conexão significativa com comportamentos e padrões atitudinais dos indivíduos, ou seja, com um padrão de cultura estabelecido. Paolo 


\section{OS JINGLES COMO FORMAS SIMBÓLICAS ESTRATÉGICAS DE PERSUASÃO POLÍTICO- ELEITORAL}

\section{FÁBIO HOFFMANN E EVERTON RODRIGO SANTOS}

Semama (1982, p.12), se refere ao fato de que um signo é uma comunicação, e como tal deve ser considerado como meio ambiental entre comunicante e sujeito, sempre observando seu potencial para induzir ao comportamento.

Como destacou Clifford Geertz ${ }^{\mathrm{X}}$, o homem é um animal preso a uma teia de símbolos significantes que ele próprio construiu. No caso brasileiro, alguns desses significados e traços podem ser encontrados em pesquisas quantitativas e qualitativas. A Pesquisa Social Brasileira (PESB) de 2002 destacou alguns traços sociais estruturais como o chamado jeitinho brasileiro, autoritarismo, estatismo, religiosidade, fatalismo e racismo $^{\mathrm{XI}}$. Eles compõem alguns elementos e sugerem algumas considerações a serem levadas em conta quando da produção de um jingle político.

Ocorre que os traços estruturais de uma sociedade são o pano de fundo da construção de um jingle político, que acaba expondo em primeiro plano um contexto histórico específico que é revelado pela conjuntura, que por sua vez tem se mostrado cada vez mais imediatista. Fernando Henrique Cardoso em 1994 focou na estabilidade econômica tendo como instrumento central o Plano Real. Funcionou, pois o recall que o eleitor possuía de uma inflação galopante fez com que elegessem esse tema como prioridade para aquela eleição. Nesse caso, o brasileiro estava nitidamente inclinado a votar em quem não somente prometia manter a inflação sob controle, mas também que tivesse contribuído para a construção da recente estabilidade. E FHC, à época Ministro da Fazenda de Itamar Franco (PMDB) e coordenador da equipe de criação da nova moeda, possuía estas credenciais.

Lula do Partido dos Trabalhadores não obteve o mesmo sucesso em eleição anterior (1989). Seu jingle "Sem Medo de Ser Feliz" de Hilton Acioli é considerado um dos melhores jingles políticos brasileiros de todos os tempos, e no qual estiveram envolvidos diversos artistas e intelectuais na construção do clipe do jingle. Falhou, no entanto, quando não levou em consideração no seu marketing de campanha, o fato da sociedade brasileira possuir traços de autoritarismo e aversão à figura do candidato radical. Sua postura referente ao não pagamento da dívida externa foi bastante explorada pelo seu adversário, Fernando Collor de Melo do (PTN) no segundo turno. Lembrando Manhanelli, o jingle é apenas parte do marketing de uma campanha, e nesse caso, como ficou claro, não deve esquecer-se do contexto histórico e social que o jingle é criado, comercializado e recepcionado.

Dessa forma, a produção de um jingle enfrenta o que Pierre Bourdieu denomina de valorização, que ocorre através da homologia funcional e estrutural, uma vez que a lógica do campo de produção e a lógica do campo de consumo devem estar objetivamente orquestradas. Não é uma tarefa fácil estabelecer nexo com o sentimento e as aspirações do eleitor e gerar empatia, pois há uma série de elementos que devem ser levados em consideração como, por exemplo, a cultura de cada região. Quanto à musicalidade na Bahia toca-se o Axé, no Rio Grande do Sul, o Vanerão; Em Goiás predomina o Sertanejo, e em Rondônia, o Forró; no Rio de Janeiro, temos o Samba, Pagode, MPB e o Funk. No Rio Grande do Sul o mito do gaúcho é um elemento simbólico muito usado em peças publicitárias, o que levou Olívio Dutra do Partido dos Trabalhadores (PT) a usa-lo intensivamente na eleição para Governador de 1998 com todo um marketing eleitoral em harmonia no sentido de reforçar esse mito ${ }^{\mathrm{XII}}$.

Destarte, um candidato que queira mobilizar emprega, usando de seus capitais (econômicos, sociais, culturais e simbólicos) e recursos, uma comunicação codificada que seja capaz de ser decodificada pelo seu público-alvo. Esse é um processo complexo, e em muitos casos, revela o motivo de alguns candidatos serem mais bem sucedidos que

Cadernos do Tempo Presente, São Cristóvão-SE, v. 08, n. 04, p. 27-38, jul./dez. 2017| http://www.seer.ufs.br/index.php/tempo 


\section{OS JINGLES COMO FORMAS SIMBÓLICAS ESTRATÉGICAS DE PERSUASÃO POLÍTICO- ELEITORAL}

\section{FÁBIO HOFFMANN E EVERTON RODRIGO SANTOS}

outros. A chave para o sucesso está no processo de criação das formas simbólicas, e o emprego de certos signos que atendam e estabeleçam a devida conexão com as aspirações e demandas daqueles que se quer mobilizar, e que também vincule um nexo codificador com sua doxa, ou seja, seus valores e crenças.

Tanto o jingle, quanto outras formas de fenômenos significativos estão submetidos a complexos processos de valorização, avaliação e conflito. Nesse sentido, "a valorização simbólica é o processo através do qual é atribuído às formas simbólicas um determinado 'valor simbólico' pelos indivíduos que as produzem e recebem,XIII. Assim, uma forma simbólica que pode ser avaliada e apreciada por uns, pode, em outros indivíduos, assumir diferenciados graus de condescendência, desprezo, aversão e até condenação.

Como uma forma simbólica é uma criação interpretativa, a partir do que Bourdieu denomina de habitus ${ }^{\mathrm{XIV}}$, e de um contexto sócio histórico, seu significado é variante e complexo, pois depende dos capitais e recursos empregados na sua codificação, bem como de uma conexão com os recursos empregados em sua decodificação. Por esse motivo seu significado é variável para diversas pessoas em diferentes sociedades, alcançando em uns, maiores significados que em outros. Nesse entendimento, uma música de protesto tem melhores resultados quando se estabelece nos signos de uma sociedade em momentos de crise, que pode ser econômica, política ou social, ou a soma delas, como foi o caso da conjuntura brasileira da década de oitenta.

O trabalho de construção do jingle político, portanto, não nasce do acaso, mas sim da confluência de um trabalho engenhoso que consagre nexo entre as aspirações e demandas do eleitor com sua cadeia de significações, projetando neles uma resposta esperada, ou seja, um produto carregado de formas simbólicas capazes de serem decodificadas. Pensa-se, por exemplo, em um jingle que reforce a esperança, um sentimento que segundo Gustave Le Bon ${ }^{\mathrm{XV}}$ é constituído de uma aptidão mental, que nos faz crer na realização de um desejo. Dessa maneira, o produtor de jingles deve conhecer bem o público que queira atingir, principalmente padrões atitudinais cristalizados por sua cultura, e que conheça bem o tipo de candidato ou governo que se queira projetar, e ainda, que faça a leitura correta do contexto sócio-histórico. Para todas estas questões as pesquisas qualitativas e quantitativas aparecem como sendo ferramentas perfeitamente úteis e necessárias quando se formula o marketing de uma campanha política moderna.

De acordo com o marketing político e eleitoral, a criação do jingle nasce com o briefing. Todavia, não é essa a argumentação deste trabalho, que por sua vez aponta para a necessidade de se conhecer o contexto histórico específico (conjuntura) e o contexto social estruturado (jeitinho, estatismo, fatalismo, religiosidade, etc.). Nesse sentido, em uma analogia útil, pode-se dizer que a cena não necessariamente deve surgir a partir do ator (o que é menos comum), mas sim da conjunção entre estória objetiva contextualizada histórica e socialmente, numa narrativa que explore em profundidade a expectativa do público. Portanto, conhecer a cultura regional e nacional, além de fazer a leitura correta da conjuntura é tão primordial quanto priorizar as qualidades do candidato. Como bem salienta Kuntz ${ }^{\mathrm{XVI}}$, o simbolismo é um recurso primordial na formação da imagem do candidato, ou governo (imagem que pode e deve ser projetada através da mensagem do jingle) e, no contexto correto, pode trazer altos ganhos de capital dentro da estratégia de marketing político e eleitoral. 


\section{OS JINGLES COMO FORMAS SIMBÓLICAS ESTRATÉGICAS DE PERSUASÃO POLÍTICO- ELEITORAL}

\section{FÁBIO HOFFMANN E EVERTON RODRIGO SANTOS}

\section{Jingle: a forma simbólica que mobiliza os sentimentos do eleitor}

"O jingle é um discurso que fala direto ao coração". Esta frase é do publicitário Duda Mendonça e se refere ao fato da força persuasiva do jingle que, quando bem elaborado, não enfrenta grandes reflexões dos indivíduos que são o público-alvo ${ }^{\text {XVII }}$. Jingles como Deixa o Homem Trabalhar, Levanta a Mão, Retrato do Velho, Sem Medo de Ser Feliz e Varre, Varre, Vassourinha foram bem sucedidos ao observar os elementos necessários da lógica dos campos de consumo e produção. "Falavam ao coração", canalizavam as demandas, aspirações e expectativas da população em uma mensagem condensada, clara e objetiva. Alguns destes jingles levaram seus candidatos à vitória, outros não conseguiram a sinergia necessária para tal. Todavia, um jingle bem feito pode ajudar a cristalizar a imagem que o político carregará consigo para o resto de sua carreira. Portanto, o jingle é parte de uma engenhosa engrenagem de ferramentas destinadas à consolidação da imagem do político para aumentos de capital (político) que serão levadas a cabo pelo marketing político e eleitoral.

A "Caixinha do Adhemar" se tornou um caso consagrado desse tipo de produção, onde uma população, ela própria, entendida na ausência de reais alternativas para representantes honestos, ao escolher de todos os que supostamente eram corruptos, preferiria escolher aquele que de alguma forma ou de outra, ainda fazia alguma coisa em benefício popular. $O$ jingle deve se estabelecer na percepção popular e dela tirar a melhor vantagem

\section{Fernando Henrique Cardoso e o mantra do Plano Real}

O Contexto sócio-histórico da campanha à Presidência da República em 1994 possuía alguns ingredientes idiossincrátcos. Primeiro, era uma eleição após um turbulento processo de impeachment que levou o primeiro presidente eleito do período da redemocratização, Fernando Collor, a renunciar em 1992, fazendo com que seu vice, Itamar Franco a assumisse o comando do país. Desde o Governo Sarney (1985-1989), o país vinha buscando a estabilização da economia através de Planos que se mostraram fracassados (Plano Cruzado, Plano Verão, Plano Collor I e II) e, nesse contexto, o pior pesadelo do brasileiro era a inflação, a qual tomava parte considerável de sua capacidade de compra. Diante de tal cenário, um discurso mais posicionado à esquerda e de cunho social começa a ganhar força, e Lula aparece liderando as pesquisas de opinião $^{\text {XVIII }}$ até meados de 1994.

Desde 1993, no entanto, a equipe econômica chefiada por Fernando Henrique Cardoso vinha trabalhando na elaboração de um plano econômico para a estabilidade monetária. De acordo com Carreirão XIX é justamente em julho de 1994 que a população começa a sentir os efeitos do Plano Real, com a queda da inflação e o aumento do poder de compra. A partir dos ganhos iniciais que o sucesso do plano proporcionou, FHC passa a endossar a mensagem que vinha transmitindo desde o ano anterior e assume a liderança das intenções de voto, o que mantém até a sua vitória em primeiro turno, com $54,24 \%$ dos votos válidos.

No marketing da campanha de FHC, com o sucesso inicial do Plano Real ${ }^{\mathrm{XX}}$, foi explorado ao máximo o apoio e sentimento de continuidade dado pela população ao Plano Real que, segundo o marketing tucano, só ele seria capaz de levar adiante, explorando também o medo de que o país regredisse novamente aos índices altos de

Cadernos do Tempo Presente, São Cristóvão-SE, v. 08, n. 04, p. 27-38, jul./dez. 2017| http://www.seer.ufs.br/index.php/tempo 


\section{OS JINGLES COMO FORMAS SIMBÓLICAS ESTRATÉGICAS DE PERSUASÃO POLÍTICO- ELEITORAL}

\section{FÁBIO HOFFMANN E EVERTON RODRIGO SANTOS}

inflação. Nesse trabalho do marketing, o jingle Levanta a Mão foi crucial para despertar esse sentimento no eleitor e ajudar a consolidar o voto, uma vez que o sucesso inicial do Plano Real já tinha transferido os votos de Lula para FHC. Observe alguns versos:

\footnotetext{
É só você olhar pra cara que você vê logo que esse sujeito é um cabra de bem (voz em of no começo do jingle)

Tá na sua mão, na minha mão, na mão da gente, Fazer de Fernando Henrique nosso presidente. Tá na sua mão, na minha mão, na mão da gente, O Brasil precisa muito da força da gente.
}

A expressão "cabra de bem", assim como o uso inteligente da voz de um cantor nordestino, aliado na segunda parte do jingle de uma voz de criança, constituem elementos que procuram projetar no eleitor o sentimento de que da sua eleição (FHC) dependem também as gerações futuras. $\mathrm{O}$ uso da voz de um cantor com sotaque nordestino também revela uma clara intenção de penetração no colégio eleitoral do nordeste, grande parte até então no vácuo deixado pelo comando do extinto Partido da Frente Liberal (PFL). No nordeste, inclusive, muito usada pelo marketing foi a foto de FHC com um chapéu de cangaceiro. Este jingle termina com uma tradicional frase de esperança "Fernando Henrique é o Brasil que vai vencer".

O determinante desta eleição foi o contexto histórico específico de um Governo Itamar muito mal avaliado, remanescente de uma crise política que culminou no impeachment de Collor. Um contexto social estruturado até então de inflação galopante, e de fracassados planos econômicos. FHC soube muito bem se projetar no momento em que o Plano Real assumia o papel de protagonista daquela eleição. Nizan Guanaes e sua equipe souberam muito bem usar das ferramentas do marketing político, dentre elas o jingle, para impulsionar a candidatura de FHC, certamente um caminho que se mostrou inequívoco, pois em 1998, apesar da crise asiática solapar as economias mundiais, refletindo, inclusive, fortemente no Brasil, ele se reelegeria em primeiro turno novamente com $53,06 \%$ dos votos válidos.

\section{Deixem o homem trabalhar}

A campanha à Presidência da República de 2006, assim como a de 1994 de FHC, possuía alguns ingredientes desafiadores para todos os candidatos: o mais singular de todos eles foi o estrago causado pelo Escândalo do Mensalão que veio a tona um ano antes.

O escândalo chegou a atingir a alta cúpula do Partido dos Trabalhadores, derrubando, inclusive o Chefe da Casa Civil de Lula, José Dirceu. No entanto, outros partidos como o Partido Trabalhista Brasileiro (PTB), de Roberto Jeferson, também fora fortemente afetados. No entanto, um elemento que contrabalançava era a boa situação econômica brasileira. O Brasil estava em pleno processo de expansão de commodities, e o sucesso do Programa Bolsa Família entre a população mais carente mostrava uma força que daria grande suporte ao governo petista.

Na oposição, José Alkimim do PSDB buscava o confronto direto com Lula, mas desde que Duda Mendonça havia conseguido emplacar a imagem do "Lula paz e amor" estava difícil encontrar uma brecha para embaraçar o petista. Duda Mendonça, percebendo que as pesquisas mostravam que o embate direto de Lula com o rival tucano

Cadernos do Tempo Presente, São Cristóvão-SE, v. 08, n. 04, p. 27-38, jul./dez. 2017| http://www.seer.ufs.br/index.php/tempo 


\title{
OS JINGLES COMO FORMAS SIMBÓLICAS ESTRATÉGICAS DE PERSUASÃO POLÍTICO- ELEITORAL
}

\section{FÁBIO HOFFMANN E EVERTON RODRIGO SANTOS}

não traria vantagens, tratou de blindar e redirecionar todos os ataques. A criação do jingle "Deixa o homem trabalhar" veio exatamente a afirmar esse conceito. Quer dizer, parem de falar mal dele (Lula), pois o país está crescendo e a pobreza está diminuindo. Assim como na campanha de FHC em 1994 e 1998, o marketing de Lula também explorou o sentimento de medo da população de trocar o "certo" pelo "duvidoso". Veja alguns trechos do jingle:

\author{
Tá tudo andando direitinho \\ Deixa o homem trabalhar \\ Ele cuida do povo com carinho \\ Eu quero o Lula lá \\ Que a gente não tem por que mudar
}

Sabe-se que o jingle é apenas parte do concatenado de peças publicitárias criadas para o sucesso no campo político. No entanto, ele deve estar em sincronia com as demais áreas do marketing, ou seja, com formulação de discursos, criação de vídeos, formatação e monitoramento das redes sociais. De nada adianta, um jingle considerado bom, como foi o caso do Sem Medo de Ser Feliz do Lula em 1989 se as demais áreas do marketing não conseguem fazer do candidato um promotor genuíno de empatia. Da mesma forma, caso a escolha do candidato se desse somente pela mensagem do jingle, Fernando Collor não teria sido eleito em 1989, pois seu jingle não era tão bom quanto à imagem de mudança projetada inteligentemente pelo seu marketing. Portanto, a conjugação do jingle com as demais peças publicitárias de uma campanha deve priorizar a sinergia para a persuasão. Compreender os elementos simbólicos presentes no contexto histórico específico e social estruturado de cada eleição e transforma-los em formas simbólicas estratégicas de persuasão eleitoral capazes de serem decodificadas de forma ampla é um desafio constante para os profissionais que trabalham na estratégia de comunicação e marketing de uma campanha moderna.

\section{Conclusão}

Além de ser uma peça publicitária, que parte de um briefing e possui função estratégica em uma campanha ou governo, o jingle, como estudado neste trabalho, é compreendido como formas simbólicas, que enfrentam um contexto histórico específíco e social estruturado quando de sua criação, transmissão e recepção. A visão publicitária do jingle como peça musicada que fala de qualidades ou rebate conceitos estabelecidos, é insuficiente quando se busca fazer incursões mais agressivas para cristalizar a imagem do candidato ou destruir um adversário no marketing de uma campanha moderna.

Analisado como formas simbólicas, fica claro o uso dos jingles políticos nas duas eleições de FHC e Lula, como instrumentos que souberam fazer uma correta leitura das expectativas daquele que era o público determinante para a vitória, conseguindo penetrar no nordeste brasileiro, além de explorar oportunamente o sentimento de temor do brasileiro em relação à mudança. Com a complexificação dos canais de comunicação, através da rápida evolução das redes e mídias sociais, as campanhas de marketing de governo e de campanha eleitoral têm sido forçadas a diversificar a produção de peças publicitárias, entre elas o jingle, pela óbvia demanda e capacidade que a configuração dessas mídias suporta.

Declarado há muito tempo o fim da comunicação unilateral, hoje as campanhas modernas necessitam de um múltiplo repertório em peças de publicidade ad hoc,

Cadernos do Tempo Presente, São Cristóvão-SE, v. 08, n. 04, p. 27-38, jul./dez. 2017| http://www.seer.ufs.br/index.php/tempo 


\section{OS JINGLES COMO FORMAS SIMBÓLICAS ESTRATÉGICAS DE PERSUASÃO POLÍTICO- ELEITORAL}

\section{FÁBIO HOFFMANN E EVERTON RODRIGO SANTOS}

feedback de qualidade e segmentação eletiva e indutiva, onde o macro e micro, online e offline, devem transfiguram-se em uma mensagem clara e objetiva. Os jingles políticos são instrumentos importantes nessa estratégia e para o fim desejado pela equipe de coordenação e marketing da campanha ou governo, que é o de ampliar o capital político de seus agentes-clientes.

\section{Notas}

${ }^{\text {I }}$ Mestrando no Programa de Pós-Graduação em Ciência Política da Universidade Federal de Pelotas UFPEL, Especialista em Marketing, Direito Eleitoral e Partidário pelo Centro Universitário Internacional - UNINTER, bacharel em Ciência Política pela Universidade Luterana do Brasil - ULBRA. E-mail: molahms@gmail.com.

II Everton Rodrigo Santos é Pós-Doutor, Doutor e Mestre em Ciência Política pela Universidade Federal do Rio Grande do Sul. É professor da Universidade Luterana do Brasil (ULBRA) e da Universidade FEEVALE.

III JENKIS, 2009.

IV THOMPSON, 2011.

V BOURDIEU, 2011.

${ }^{\mathrm{VI}}$ MANHANELLI, 2011.

VII De forma contrária ao esperado, em março de 2010 Dilma aparecia atrás de Serra na preferência do voto feminino nas sondagens de todos os institutos. Com o avanço da campanha, no entanto, Dilma consegue aumentar sua presença no eleitorado feminino onde Serra perde terreno. Ver A Reversão Das Expectativas de Gênero Nas Eleições de 2010: Dilma na frente entre os homens e Serra na frente entre as mulheres (ALVES, 2010) em: http://www.ie.ufrj.br/aparte/pdfs/art 70 expectativa de genero.pdf, em 10/02/2017; e O Voto Das Mulheres Pesa para Crescimento de Dilma e Queda de Serra (JORDÃO, 2010) em: $\quad$ http://www.spm.gov.br/assuntos/poder-e-participacao-politica/referencias/politica-egenero/o voto dasmulheres pesa par.pdf, em 10/02/2017.

VIII Conceito usado por MANHANELLI, 2011.

IX THOMPSON, 2011, p. 180-182.

X GEERTZ, 1978.

XI ALMEIDA, 2007.

XII MOURA, 2006.

XIII THOMPSON, 2011, p. 203

XIV De acordo com Pierre Bourdieu, o habitus é um princípio gerador de práticas objetivamente classificáveis e, ao mesmo tempo, sistema de classificação de tais práticas. Estruturas, estruturadas e estruturantes, ou seja, padrões nas maneiras de agir e pensar, e até o comportamento corporal.

XV LE BOM, 1956, p. 20-21.

${ }^{\mathrm{XVI}}$ KUNTZ, 2006, p. 52-53.

XVII MENDONÇA, 2001.

XVIII Segundo dados do DataFolha, Lula possuía 42\% das intenções de voto em maio de 1994, enquanto FHC possuía apenas 16\%. Já em julho os dois aparecem tecnicamente empatados, com $32 \%$ e $29 \%$, respectivamente. Em outubro, no entanto, FHC aparece com $48 \%$, enquanto Lula aparecia com $22 \%$. Ver DataFolha, disponível

http://media.folha.uol.com.br/datafolha/2013/05/02/intvoto pres 01101994.pdf.

XIX CARREIRÃO, 2002, p. 121.

XX Em três pesquisas do DataFolha em pergunta aberta, sobre as motivações do voto em FHC, o Plano Real respondia por 45 à 60\% das menções. (CARREIRÃO, p.121).

\section{Referências:}

ALMEIDA, Alberto Carlos. A Cabeça do brasileiro. Rio de Janeiro: Record, 2007. 
AZARITE, Ricardo. Ferramentas e cases para fazer campanhas políticas em redes sociais. Disponível em: http://docplayer.com.br/1982600-Ebooks-ferramentas-e-casespara-fazer-campanhas-politicas.html. Acesso em: 06/07/2018.

BOURDIEU, Pierre. A Distinção: crítica social do julgamento. Porto Alegre: Zouk, 2011.

CARREIRÃO, Yan de Souza. A Decisão do voto nas eleições presidenciais brasileiras. Florianópolis: Ed. da UFSC; Rio de Janeiro: FGV, 2002.

DATAFOLHA. Relatório de pesquisa. Disponível em http://media.folha.uol.com.br/datafolha/2013/05/02/intvoto_pres_01101994.pdf. Acesso em 05/07/2018.

GEERTZ, Clifford. A Interpretação das culturas. Rio de Janeiro: Zahar, 1978.

JENKINS, Henry. Cultura da convergência. São Paulo: Aleph, 2009.

KUNTZ, Ronald A. Marketing político: manual de campanha eleitoral. São Paulo: Global, 2006.

LE BON, Gustave. As Opiniões e as crenças. Rio de Janeiro: Cia Brasil, 1956.

MANHANELLI, Carlos. Jingles eleitorais e marketing político: uma dupla do barulho. São Paulo: Summus, 2011.

MENDONÇA, Duda. Casos e coisas. São Paulo: Globo, 2001.

MOURA, Paulo. O Gauchismo no marketing de Olívio Dutra. PGM, Porto Alegre, 2006.

SEMAMA, Paolo. Linguagem e poder. Brasília: Universidade de Brasília, 1981.

THOMPSOM, John B. Ideologia e cultura moderna: teoria social crítica na era dos meios de comunicação de massa. Petrópolis: Vozes, 2011.

Cadernos do Tempo Presente, São Cristóvão-SE, v. 08, n. 04, p. 27-38, jul./dez. 2017| http://www.seer.ufs.br/index.php/tempo 